\title{
REPORT ON THE PRECISION OF ATOMIC STANDARDS OF FREQUENCY
}

By L. ESSEN

National Physical Laboratory, Teddington, England

\begin{abstract}
Atomic frequency standards have been checked by laboratory investigations and by the intercomparison of different standards.

Existing ammonia Masers enable a frequency to be defined in terms of a spectral line with an accuracy of $\pm \mathbf{I}$ part in $10^{8}$ and give a reproducibility under stated conditions of \pm 2 parts in $10^{10}$. The cesium atomic beam standard enables a frequency to be defined in terms of a spectral line with a precision of $\pm I$ part in $10^{10}$. Comparison between the U.K. and U.S. by the radio transmissions of standard frequencies and time signals gave an average agreement of a few parts in $10^{10}$ but revealed some systematic discrepancies. Direct comparisons between three U.S. standards and the U.K. standard gave agreement to $2.2,3.2$, and 1.5 parts in $10^{10}$.
\end{abstract}

I. Introduction. Any radio frequency spectral line is a potential standard of frequency and the choice depends largely on practical considerations. So far two lines only have been used, the $J=3, K=3$ line of the inversion spectrum of ammonia and the $F, m(4,0) \rightleftarrows F, m(3,0)$ hyperfine splitting line of cesium $^{133}$. The techniques employed in order to approach as closely as possible the true line frequency have been described and this report is concerned only with the precision obtained. The results quoted include some work which is in course of publication but the information may not be complete as there is much further work in progress.

There are three ways of testing the precision of frequency standards:

(a) The parameters that can vary in practice are varied deliberately and the effect is measured by comparison with another standard which remains unaltered.

(b) Standards of different construction are directly compared.

(c) Standards of different construction are compared by means of standard frequency transmissions or time signals.

All of these methods have been used and it will be convenient to discuss the results separately for the two types of standard.

2. Ammonia standards. In the early work on ammonia in the U. S. and Japan the absorption line was used which was of the order of $10^{5}$ cycles/ second wide at a frequency of $2.3870 \times \mathrm{IO}^{10}$ cycles/second. Techniques were developed for setting on the center of the line and an accuracy of $5 \times 10^{-9}(100 \mathrm{c} / \mathrm{sec})$ has been claimed; but it is difficult to regard a line having such a width as forming a precise standard. A fundamental improvement was suggested by N. G. Basov and A. M. Prokhorov and by J. P. Gordon, H. J. Zeiger and C. H. Townes, which enabled the line width to be reduced to $7 \mathrm{kc} / \mathrm{sec}$, in the device now well known as the Maser. A comparison between

two similar Masers showed that a stability of $\mathrm{I} \times \mathrm{IO}^{-11}$ could be maintained for a short time; but it was known from both theory and experiment that the external parameters could pull the frequency from that corresponding to the center of the line. For this reason it has proved difficult to define the frequency of operation in terms of the spectral line with a precision exceeding $\pm \mathbf{I}$ part in $10^{8}$. An extensive investigation has been carried out by J. Bonanomi and his collaborators at Neuchâtel and they have found that if a particular Maser is set according to a definite procedure a reproducibility of \pm 2 parts in $10^{10}$ can be achieved. It has been found that some of the difficulty arises from the fact that the $\mathrm{NH}_{3}$ $(3,3)$ line is a multiplet and not a single line.

Time signals from Neuchâtel (HBN) and other signals received at Neuchâtel have since July 1957 been expressed in terms of a Maser frequency of $23,870,129,235 \mathrm{c} / \mathrm{sec}$. It has thus been possible to make a comparison with the N.P.L. cesium standard. The results are given in Table I.

The mean difference is of no significance since it depends on the values adopted for the spectral line frequencies but the deviations from the mean represent changes of the Maser frequency relative to that of the cesium standard apart from any errors in relating the transmitted frequency to the Maser frequency or due to the radio propagation conditions.

3. Cesium standards. The cesium standard at

TABLE I. COMPARISON BETWEEN NEUCHÂTEL MASER AND N.P.L. CESIUM STANDARD

Date
July 1957
Aug. I957
Sept. I957
Oct. I957
Nov. I957
Dec. I957
Jan. I958 
TABLE II. COMPARISON BETWEEN ATOMICHRONS WITH N.P.L. CESIUM STANDARD

Date Values of Atomichrons-

Atomichron No. IOO (Camden)

$\begin{array}{lr}\text { Nov. I956 } & -7 \\ \text { Dec. } & -2 \\ \text { Jan. I957 } & -6 \\ \text { Feb. } & -8 \\ \text { Mar. } & -5 \\ \text { Apr. } & 0 \\ \text { May } & -2\end{array}$

Atomichron No. 106 (Boulder)

Oct.

Nov.

Dec.

Jan. $195^{8}$

$+15$

$+18$

Feb.

$$
\begin{aligned}
& +22 \\
& +15
\end{aligned}
$$

Atomichron No. II2 (Harvard)

$\begin{array}{lr}\text { Mar. } & +2 \\ \text { Apr. } & +1 \\ \text { May } & \text { o } \\ \text { June } & 0\end{array}$

the N.P.L. has been in operation since June 1955 and those constructed by the National Company Inc., U. S. since the autumn of 1956 . A considerable amount of information concerning their performance has therefore been accumulated. The N.P.L. standard was built so that the effect of varying the parameters could be studied and the results of this investigation have been published. Copies of the paper have been circulated to members of Commission 3I. It was concluded from the investigation that the only two parameters that needed careful definition were the magnetic field and the relative phases of the two regions of r.f. magnetic field; and that these parameters could be readily set to give a precision of frequency of a few parts in $\mathrm{IO}^{11}$. The experimental model served for routine calibration of the $100 \mathrm{kc} / \mathrm{sec}$ quartz clocks used as working standards with a precision of $\pm \mathrm{I}$ part in $1 \mathrm{I}^{10}$ and under good conditions the accuracy of setting to the cesium resonance is \pm 5 parts in $10^{11}$.

The National Co. standard, known as the Atomichron, is used with a servo control equipment to correct a quartz oscillator of nominal frequency $5 \mathrm{Mc} / \mathrm{sec}$ and maintain it in a fixed relationship of I/I, 838.526368 with the cesium frequency. The results of an investigation of its performance by the National Co. is in course of publication.

It has been compared with the N.P.L. standard by means of standard frequency transmissions and by time signal comparisons. The former method can be carried out fairly quickly, measurements extending over an hour or so giving a precision of $\pm \mathrm{I}$ part in $1 \mathrm{I}^{10}$ but it is necessary to take account of variations in the propagation conditions. It is believed that over parts of the day, the propagation of low frequencies, such as the MSF $60 \mathrm{kc} / \mathrm{sec}, \mathrm{GBR} \mathrm{I} 6 \mathrm{kc} / \mathrm{sec}$ and $\mathrm{GBZ}$ $19.6 \mathrm{kc} / \mathrm{sec}$ signals is sufficiently stable to give an accuracy of $\pm I$ part in $10^{10}$. J. A. Pierce at Harvard has measured his local standards in terms of these transmissions and also in terms of a transmission controlled or monitored by an Atomichron. In this way the two atomic standards have been compared and the results are summarized in Table II, in which the average monthly values are given.

The difficulties inherent in such a complicated chain of comparison were sometimes severe, and the conditions for the comparison with No. 106 were particularly unsatisfactory the standard deviation of these results being about $\pm 15 \times$ $10^{-10}$. The results with No. I 12 which is situated at Harvard and thus affords the simplest chain of comparison are very satisfactory the standard deviation being $\pm 3 \times 10^{-10}$.

Comparisons have also been made by means of time signals. In a joint program of work between the U. S. Naval Observatory and the N.P.L. which was begun in the summer of 1955 in order to establish the relationship between the cesium frequency and the second of ephemeris time, the interval between selected time signals is measured in terms of cesium at the N.P.L. and astronomical time at the U. S. Naval Observatory. Since the autumn of 1956 an Atomichron has also been measured at the U. S. Naval Observatory thus giving a comparison between the Atomichron and the N.P.L. standard. These results are summarized in Table III.

TABLE III. COMPARISON BETWEEN U.S. NAVAL OBSERVATORY ATOMICHRON WITH CESIUM STANDARD

\begin{tabular}{|c|c|}
\hline Date & $\begin{array}{l}\text { Atomichron No. } 6-\text { N.P.L. } \\
\text { Cs parts in } 10^{10}\end{array}$ \\
\hline Sept. I956 & -6 \\
\hline Oct. & -12 \\
\hline Nov. & -14 \\
\hline Dec. & -18 \\
\hline Jan. I957 & -10 \\
\hline Feb. & -7 \\
\hline Mar. & -10 \\
\hline Apr. & -6 \\
\hline May & O \\
\hline June & +2 \\
\hline July & $+\mathbf{I}$ \\
\hline Aug. & +10 \\
\hline Sept. & +8 \\
\hline Oct. & $+\mathrm{I} 2$ \\
\hline Nov. & +6 \\
\hline Dec. & +28 \\
\hline Jan. I958 & +20 \\
\hline Feb. & +II \\
\hline Mar. & -4 \\
\hline
\end{tabular}


In Tables II and III, an allowance has been made for the slightly different magnetic fields used in the N.P.L. standard and the Atomichron and for the different numbers by which the cesium frequency is divided.

They show a somewhat larger difference between the two standards than the frequency measurements and this discrepancy up to June I 957 was discussed by the Consultative Committee for the Definition of the Second of the International Committee of Weights and Measures and also at the Boulder (1957) meeting of U.R.S.I. It was urged that direct comparisons should be instituted in order to eliminate the errors possibly associated with radio propagation.

Dr. Markowitz has also supplied the results given in Table IV of comparison in the U. S. between different Atomichrons. They probably do not explain the discrepancy but they show that small differences occur in operation between the frequencies of different models.

During March 1958 a series of direct comparisons were made at the N.P.L., Teddington, England, between two Atomichrons, Nos. I I I and II7, an experimental beam tube $857 \mathrm{XI}$ made by the National Co. and the N.P.L. standard. Members of the staff of the National Co. Inc. and the U. S. Army Signal Engineering Laboratories assisted in these measurements. The results in Table $\mathrm{V}$ give the reproducibility of the Atomichron frequencies after resetting the electronic circuits associated with the servo mechanisms following a standard alignment procedure. The N.P.L. quartz clock Q13 was in some cases used for interpolation over short time intervals and the results for this clock given in Table $\mathrm{V}$ illustrate the general uniformity of drift rate obtained. The limits represent the standard deviation of a single observation.

The Atomichron beam tubes were then tested as resonators with the N.P.L. driving source.

\begin{tabular}{|c|c|c|}
\hline Date & Atomichron designations & $\begin{array}{l}\text { Frequency } \\
\text { difference } \\
\text { parts in } 10^{10}\end{array}$ \\
\hline $\begin{array}{l}\text { Nov. I } 956 \text { to } \\
\text { June I }\end{array}$ & 6 (NRL)-I (Camden N. Y.) & -3 \\
\hline $\begin{array}{l}\text { Oct. I957 } \\
\text { (second half } \\
\text { of month) }\end{array}$ & 6 (NRL)-IO6 (Boulder) & +4 \\
\hline Nov. & 6 (NRL)-I06 (Boulder) & 0 \\
\hline Dec. & 6 (NRL)-I06 (Boulder) & 0 \\
\hline Jan. I958 & 6 (NRL)-I06 (Boulder) & +3 \\
\hline Feb. & 6 (NRL)-106 (Boulder) & -3 \\
\hline Mar. & 6 (NRL)-I06 (Boulder) & -4 \\
\hline
\end{tabular}

TABLE V. FREQUENCY REPRODUCIBILITY AFTER REALIGNMENT

Unit I $\times 10^{-10}$

\begin{tabular}{|c|c|c|c|c|c|}
\hline \multicolumn{2}{|c|}{ Date 1958} & III-N.P.L. & $\begin{array}{l}\text { Frequency } \\
\text { I } 7 \text {-N.P.L. }\end{array}$ & $\begin{array}{l}\text { Aifference } \\
\text { (857 XI } \\
\text { +III servo) } \\
\text { N.P.L. }\end{array}$ & $\begin{array}{l}\text { Q13- } \\
\text { N.P.L. }\end{array}$ \\
\hline Mar. & 6 & 3.6 & 3.5 & & 230.0 \\
\hline & 7 & 3.8 & 3.6 & & 231.8 \\
\hline & IO & & $3 \cdot 3$ & & 233.5 \\
\hline & I I & & 4.0 & & 233.6 \\
\hline & 12 & & 3.2 & 4.7 & 234.5 \\
\hline & 14 & & 2.5 & 4.2 & 23 \\
\hline & 17 & 4. I & 3.5 & & 238.2 \\
\hline & I8 (a.m.) & 3.7 & 3.7 & & 239.4 \\
\hline & I 8 (p.m.) & 3.6 & 2.7 & & 238.1 \\
\hline & I9 (a.m.) & $4 \cdot 3$ & $3 \cdot 3$ & & 240.2 \\
\hline & I9 (p.m.) & 4.0 & 3.2 & & 240.0 \\
\hline & 20 (a.m.) & 3.9 & 3.1 & & 240.7 \\
\hline & 20 (p.m.) & 4.5 & & & $24 \mathrm{I} .4$ \\
\hline & 24 (a.m.) & 3.5 & 3.4 & & 244.7 \\
\hline & 24 (p.m.) & 3.6 & 2.8 & & 244.8 \\
\hline & 24 (p.m.) & 3.8 & $3 \cdot 3$ & & 245.5 \\
\hline & 26 & 3.4 & & & 244. I \\
\hline & 28 & 3.2 & & & 245.8 \\
\hline Apr. & I (a.m.) & 3.5 & 3.0 & & 249.2 \\
\hline & I (p.m.) & 3.7 & 2.9 & & 249.6 \\
\hline & 2 & 3.5 & 3.2 & & 250.7 \\
\hline Mean & & $3.7 \pm 0.3$ & $3.2 \pm 0.4$ & $4.5 \pm 0.3$ & \\
\hline
\end{tabular}

Owing to the greater length of the Atomichron tubes and their resulting lower band widths they could be used with slightly greater precision than the N.P.L. beam tube and it is believed that a setting accuracy of \pm 2 parts in $10^{11}$ was achieved. The measurements were used in an attempt to analyze the effects that could cause the frequency to depart from the true line frequency, and these results are reproduced in Table VI.

The measured errors due to the servo, electronics and asymmetry can legitimately be applied as corrections to the mean frequencies of Table $\mathrm{V}$ and the final results of the comparisons are then as follows:

$$
\begin{aligned}
\text { I I I-N.P.L. } & 2.2 \pm \mathrm{I} .4 \times \mathrm{Io}^{-10} \\
\text { I I 7-N.P.L. } & 3.2 \pm \mathrm{I} .4 \times \mathrm{IO}^{-10} \\
857 \text { XI-N.P.L. } & 1.5 \pm \mathrm{I} .4 \times \mathrm{IO}^{-10}
\end{aligned}
$$

4. New developments. This subject is developing so rapidly that a new and important advance has been disclosed since the first draft was prepared. If a buffer gas, such as argon at pressures up to $30 \mathrm{~mm} \mathrm{Hg}$ is included with cesium vapor, collisions of the cesium atoms with the buffer gas

\begin{tabular}{|c|c|c|c|c|}
\hline \multirow[b]{2}{*}{ Effect } & \multicolumn{4}{|c|}{ Frequency error } \\
\hline & I I I & II 7 & $\begin{array}{l}857 \mathrm{NI} \\
+\mathrm{IIIe}\end{array}$ & N.P.L. \\
\hline Servo \& electronics & $+8 \pm 4$ & $+6 \pm 4$ & $+20 \pm 4$ & 0 \\
\hline Asymme & $-3 \pm 7$ & $-16 \pm 7$ & $0 \pm 7$ & $-10 \pm 10$ \\
\hline po & $+4 \pm 2$ & $+9 \pm 2$ & $0 \pm 2$ & $0 \pm 5$ \\
\hline
\end{tabular}

TABLE VI. BEAM TUBES TESTED AS RESONATORS Unit $1 \times 10^{-11}$ 
do not produce transitions but greatly reduce the average velocity in a particular direction, and hence the broadening of a line due to the Doppler effect. An optical means of detecting transitions between the hyperfine levels has given an increased sensitivity and a line $40 \mathrm{c} / \mathrm{sec}$ wide (in 9,192 Mc/sec) has been observed. The actual frequency is influenced by the buffer gas, however, and the new techniques do not at present provide a definitive standard.

5. Conclusions. It is concluded from this review that the Maser-type ammonia standard can be used to define frequency in terms of a spectral line with an accuracy of $\pm \mathrm{I}$ part in $1 \mathrm{O}^{8}$ and that the reproducibility of a carefully defined Maser is considerably better.

Existing cesium standards can be used to define frequency in terms of a spectral line with an accuracy of \pm 2 parts in $10^{10}$ and the results have been integrated throughout a time interval of three years for the purpose of comparing atomic and astronomical times.

There are goods reasons for believing that the accuracy of the atomic beam-type of cesium standard can be increased by at least ten times and that experiments with new techniques such as optical pumping, and the use of buffer gases will lead to simpler forms of standard.

\section{DISCUSSION}

Dr. STOYKO commented that even though the atomic standard is not a clock, it can still be used as a time-keeper through the intermediary of quartz clocks. It has been possible, through the kindness of Dr. Decaux, to use Atomichron No. 107 at the National Laboratory of Radioelectricity in Bagneux to interpolate from the atomic time at the Time Service of the Observatory of Paris and the International Bureau of Time. This atomic standard is compared each day with three quartz clocks which, in turn, are compared with the Time Service at the Observatory of Paris. The integration of frequency of the atomic standard in conjunction with these three quartz clocks permits control of the precision of time maintenance by this method. Since March I $95^{8}$ this method has been used for the direct interpolation of the correction of the main clock according to the atomic observations of the Observatory of Paris. Since the conventional frequency of the atomic standard does not correspond to the exact second with the provisional Uniform Universal Time (UT2) which is the basis of time services, the correction of the atomic clock must be represented as calculated by a linear function which is of a sufficient precision for an interval of the order of two months.

Prof. MIKHAILOV, the Chairman, asked how long a cesium standard would run.

Dr. ESSEN reported that in the United Kingdom it has been arranged to use the standard which controls the standard frequency transmissions for generating the signals for the time service of the Royal Greenwich Observatory. If the frequency remains as at present based on a value of $9,192,631,830 \mathrm{c} / \mathrm{sec}$ for the cesium reson- ances step adjustments of about one per month would be made to the signals to keep them reasonably close to UT2. If the frequency were changed to $9,192,631,770 \mathrm{c} / \mathrm{sec}$, the value in terms of the second of ephemeris time still more frequent adjustments would be required. It is therefore proposed to operate the service in the following way:

The frequency of $9,192,631,770 \mathrm{c} / \mathrm{sec}$ will be used as the standard but the service will operate with an error of about +160 parts in $10^{10}$ so as to bring the frequency and time pulses in close accord with the time scale of UT2. Corrections published by the Royal Greenwich Observatory will give the errors from UT2. Corrections published by the National Physical Laboratory will give the errors from the cesium frequency of $9,192,631,770 \mathrm{c} / \mathrm{sec}$ to $+\mathrm{I}$ part in $10^{10}$. This will also be the error from ephemeris time with the lower precision of \pm 20 parts in $10^{10}$. All possible time and frequency information will thus be given by the service.

Dr. MARKOWITZ commented that the operation of a cesium clock does not require that the cesium beam itself shall be in operation continuously. The cesium clock at the Naval Research Laboratory, Washington, D. C., consists of a cesium beam frequency standard which is operated in conjunction with a quartz-crystal clock of high precision which indicates time. The quartz-crystal clock is operated continuously, and is adjusted in frequency daily to that of the cesium standard. It is not necessary, therefore, to operate the cesium beam continuously, and in fact, the beam itself may be changed.

(End of Symposium) 